\title{
EJAAN BAHASA SASAK
}

\section{SASAK LANGUAGE SPELLING}

\author{
Lalu Erwan Husnan
}

Kantor Bahasa Provinsi NTB

laluhusnan@gmail.com

Tanggal naskah masuk: 24 Oktober 2012

Tanggal revisi terakhir: 2 November 2012

\begin{abstract}
Sasak is one of local language which has the highest amount of speakers in West Nusa Tenggara (NTB). It is used by Sasak ethnic group. It is included into Bali-Sasak-Sumbawa group of language. Study on standardization of Sasak as well as spelling used linguistic and sociolinguistic consideration. As a result, a-a dialect has been agreed to be standard. Besides using linguistic and sociolinguistic consideration, this dialect has the highest number of speakers than the other dialects. This choice is based on economical principle, clarity, unity, and integrity. On the other side, elements of other dialects are picked up for the purpose of standardization and teaching Sasak.
\end{abstract}

Keywords: Sasak, standardization, spelling

\begin{abstract}
Abstrak
Bahasa Sasak merupakan salah satu bahasa dengan penutur paling banyak di Nusa Tenggara Barat (NTB). Bahasa Sasak digunakan oleh etnis Sasak sebagai bahasa sehari-hari. Bahasa ini masuk dalam kelompok bahasa Bali-Sasak-Sumbawa. Kajian standardisasi bahasa Sasak termasuk ejaannya menggunakan pertimbangan linguistik dan sosiolinguistik. Hasilnya, dialek aə memiliki peluang untuk dijadikan ejaan standar. Selain menggunakan pertimbangan linguistik dan sosiolinguistik, dialek ini juga memiliki penutur paling banyak dibandingkan dengan dialek yang lain. Pemilihan ini didasarkan pada beberapa prinsip, yaitu prinsip kehematan, kejelasan, semangat persatuan, dan integritas sosial. Di lain pihak, unsur-unsur dari dialek lainnya diambil untuk kepentingan standardisasi dan pembelajaran.
\end{abstract}

Kata kunci: sasak, standardisasi, ejaan

\section{Pendahuluan}

Bahasa Sasak merupakan satu di antara tiga bahasa daerah (ibu) di Nusa Tenggara Barat yang memiliki penutur paling banyak. Bahasa Sasak digunakan oleh etnis Sasak yang mayoritas mendiami Pulau Lombok. Bahasa Sasak sendiri masuk dalam kelompok bahasa Bali-SasakSumbawa ${ }^{1}$. Berbagai penelitian telah dilakukan oleh para linguis, mulai dari Thoir (1985/86) sampai Mahsun
(1997). Penelitian tersebut banyak fokus pada bidang leksikon. Namun begitu, kajian yang fokus pada masalah standardisasi bahasa Sasak belum menjadi perhatian mereka. Adapun penelitian standardisasi pernah dilakukan oleh Bappeda Provinsi NTB $(2005)^{2}$, tapi masih belum mampu mencerminkan kesejatian bahasa Sasak karena menggunakan struktur bahasa Indonesia dan belum ditentukan dialek 
mana yang digunakan dalam membuat standardisasi. Salah satu pekerjaan rumah besar dalam kajian standardisasi adalah ejaan mana yang menjadi bentuk standar berdasarkan kajian ilmiah. Persoalan ini tidak bisa dilihat dari segi linguistik saja tapi juga dari segi sosilinguistik. Hal ini dilakukan untuk memperoleh pertimbangan sosiologis dengan mengetahui sikap bahasa masing-masing penutur dialek, pertimbangan linguistik dan sosiolinguistik.

Berdasarkan pada hasil kajian dengan mempertimbangkan faktor linguistik dan sosiolinguistik, Kajian Standardisasi Dialek Bahasa Sasak yang dilakukan oleh Sirulhaq, dkk. ${ }^{3}$ lebih cenderung mendukung ke arah pilihan bahasa Sasak yang paling berpeluang untuk dijadikan dialek standar, yaitu bahasa Sasak dialek a-ə (Pujut) ${ }^{1}$. Pilihan ini juga didasarkan pada faktor jumlah penutur dialek tersebut paling banyak dibanding dengan Dialek a-a (Bayan), Dialek ə-ə (Selaparang), dan Dialek a-つ (Aiq Bukaq).

Adapun alasan pemilihan Dialek a-ə sebagai dialek standar didasarkan pada prinsip kehematan, prinsip kejelasan, semangat persatuan, dan integritas sosial serta mengambil unsurunsur dari dialek lainnya untuk kepentingan standardisasi dan pembelajaran. Oleh karena itu, buktibukti lingusitik yang ingin dijadikan acuan (segi fonologi sampai sintaksis dan ketataaksaraan) haruslah konsisten diterapkan. Hal ini bertujuan supaya tidak terjadi kerancuan dalam pemahaman hal ihwal tentang bahasa Sasak standar. Prinsip kehematan dimaksudkan supaya pengelolaan tatabahasa seperti untuk keperluan pengajaran mudah dilakukan. Berikut akan dijabarkan secaralebih rinci alasan penetapan secara linguistik dan ekstralinguistik.

\section{Metode}

Mengingat data yang digunakan dalampenelitian ini adalah data-data kebahasaan yang bersifat empirik, maka metode relevan yang digunakan untuk menjaring adalah metode cakap semuka dengan teknik lanjutan teknik pancing, simak, cakap, dan rekam ${ }^{4}$. Adapun metode analisis yang digunakan adalah metode Padan Intralingual, metode Agih, dan metode Deskriptif-Interpretatif.

Metode Padan Intralingual meliputi teknik hubung banding menyamakan (HBS), teknik hubung banding membedakan (HBB), dan teknik hubung banding menyamakan hal pokok (HBSP) ${ }^{5}$. Pada praktiknya, teknik lanjutan hubung banding dengan semua unsur penentu yang relevan dengan unsur data yang tetapkan sebelumnya. Karena tujuan akhir dengan menggunakan metode ini adalah mencari hal pokok, maka langkah berikutnya adalah membandingkan hal yang pokok.

Teknik dasar metode Agih adalah teknik dasar bagi langsung (BUL), dan 
teknik lanjutannya adalah teknik lesap, teknik ganti, teknik perluas, teknik sisip, teknik ubah wujud, dan teknik ulang $^{6}{ }^{7}$. Teknik dasar bagi langsung memungkinkan kalimat atau satuan lingual bahasa Sasak dibagi menjadi beberapa konstituen. Teknik lanjutannya yaitu melesapkan unsur tertentu satuan lingual bahasa Sasak, menggantikan unsur tertentu satuan lingual bahasa Sasak dengan unsur di luar satuan lingual tersebut, memperluas satuan lingual tersebut ke kiri atau ke kanan dengan menggunakan unsur tertentu, menyisipkan unsur lain di antara unsurunsur satuan lingual tersebut, memindahkan posisi satuan lingual pada posisi lainnya, mengubah wujud satuan lingual dengan bentuk yang berbeda, dan mengulang unsur satuan lingual tersebut.

Metode ketiga bertujuan untuk mengetahui sikap penutur bahasa Sasak berkaitan dengan dialek yang mereka gunakan dan dialek lain dalam bahasa Sasak.

\section{Prinsip Penetapan Fonem Bahasa} Sasak Standar

Adapun fonem-fonem yang dijadikan standar merupakan fonem yang tidak lain diambil dari bunyibunyi bahasa Sasak yang ada dalam salah satu dialek bahasa Sasak. Penentuan tersebut dilakukan menggunakan beberapa langkahlangkah penting. Pertama, setiap pasangan minimal yang dapat menimbulkan makna berbeda pada satuan leksikal yang dipasangkan maka dianggap fonem yang berbeda. Misalnya, bentuk [api] 'api'/i/, [apə] 'apa'/ə/, [sidUt] 'sendok'/d/,

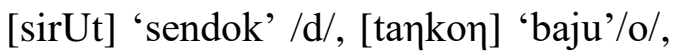

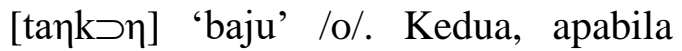
sebuah bunyi tidak memiliki pasangan minimal, tapi ia memiliki pasangan distingtif yang mirip dengan bunyi yang lain, dan masing-masing kemiripan memiliki distribusi yang komplementer dalam sebuah satuan leksikal yang berbeda, maka bunyibunyi tersebut dianggap alofon dari sebuah fonem yang sama.Misalnya, /x/ menjadi $[\mathrm{x}]$ / u terbuka dan menjadi $[\mathrm{x}]$ pada posisi lain (bisa lebih dari satu; bisa beraturan bisa juga tidak). Ketiga, khusus untuk bunyi vokal, apabila tidak memiliki pasangan minimal dan tidak memiliki distribusi yang komplementer dengan bunyi yang memiliki fitur distingtif yang mirip dengannya, namun keberadaannya memiliki hubungan yang simetris dengan bunyi yang lain, maka ia dianggap sebuah fonem. Perhatikan diagram vokal berikut. 


\section{Bunyi-bunyi Bahasa yang Simetris}

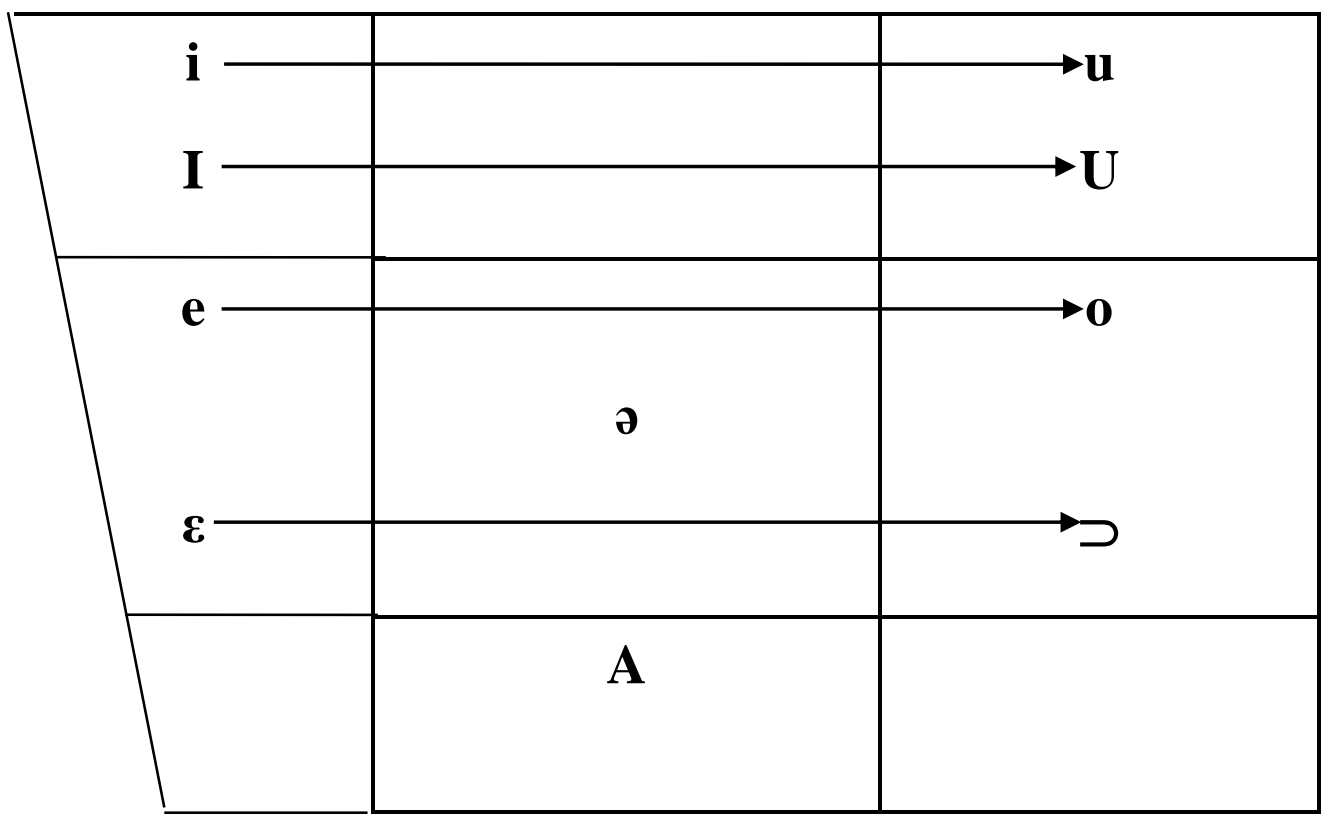

Jika dalam bahasa Sasak

ditemukan fonem /e/ maka bisa dihipotesiskan bahwa dalam bahasa Sasak terdapat juga fonem /o/, demikian sebaliknya karena dalam setiap bahasa kehadiran fonem yang simetris tersebut dalam satuan leksikal selalu serempak.Misalnya, [geoך] 'ayunan' /e/; /o/dan

\begin{tabular}{|c|c|}
\hline contoh & glos \\
\hline təlu & 'tiga' \\
\hline tələ & 'nakal' \\
\hline $\mathrm{t} \supset \varepsilon \mathrm{q}$ & 'belah' \\
\hline $\mathrm{t} \supset \mathrm{aq}$ & 'tua' \\
\hline tuaq & 'paman' \\
\hline sili & 'marah' \\
\hline silə & 'sila (bersial)' \\
\hline kado & 'lacur' \\
\hline kadu & 'pakai' \\
\hline kere & 'sarung/kain' \\
\hline
\end{tabular}

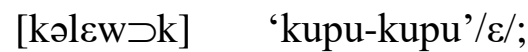
/./.

Bunyi vokal dalam bahasa Sasakadalah 1) bunyi vokal u dan ə; 2) bunyi vokal $\varepsilon$, a, $\supset$, dan u; 3) bunyi vokali;bunyi vokal o; 4) bunyi vokal e. Secara berurutan dapat dilihat pada tabel berikut.

bunyi

[D]

$[\varepsilon]$

$[\supset, \mathrm{a}]$

[i]

[e] 
Alofon Fonem Vokal dalam Bahasa Sasak

1. Kaidah alofon fonem $/ \mathrm{u} /$

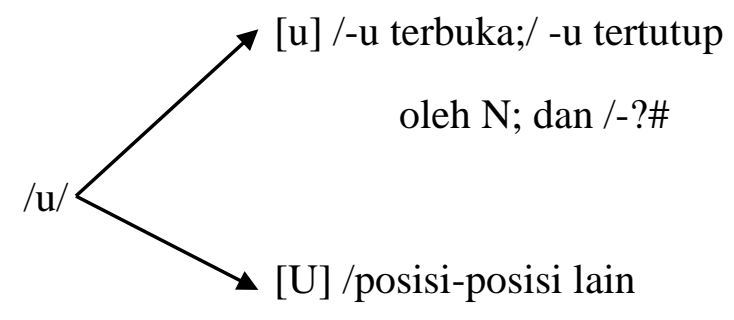

Contoh:

[əmpUk]

'pukul'

[səbUr]

[ləbUr]

'sebur/siram'

[batUr]

'lebur'

[umbaq]

'teman'

'gendong'

[umbak]

[kadu]

'ombak'

[tulak]

'pakai'

'balik'

2. Kaidah alofon fonem /i/

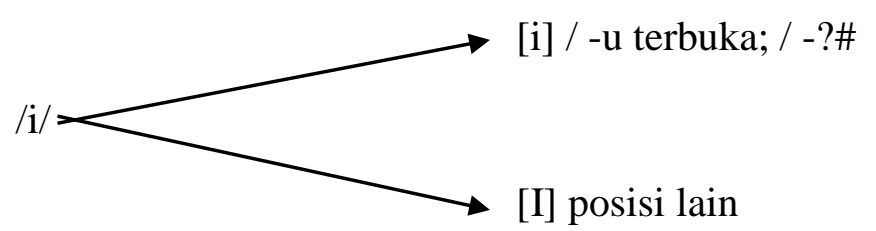

$\begin{array}{llll}\text { [baIt] } & \text { 'ambil' } & \text { [salIn] } & \text { 'ganti' } \\ \text { [inaq] } & \text { 'ibu' } & \text { [iraq] } & \text { 'ajak' } \\ \text { [imbuq] } & \text { 'pungut' } & {[\text { siram] }} & \text { 'siram' } \\ \text { [sili] } & \text { 'marah' } & {[\text { silə] }} & \text { ' 'bersila' } \\ \text { [tali] } & \text { 'tali' } & \text { [sədi] } & \text { 'pingir' }\end{array}$


Konsonan dalam Bahasa Sasak

\begin{tabular}{|c|c|c|c|c|c|c|c|c|c|}
\hline \multirow[t]{3}{*}{$\mathbf{I}$} & \multirow[t]{3}{*}{ II } & \multicolumn{8}{|c|}{ Daerah Artikulasi dan Artikulator } \\
\hline & & \multirow{2}{*}{$\begin{array}{l}\text { Labial } \\
\text { Labial }\end{array}$} & \multicolumn{2}{|c|}{ Dental } & \multicolumn{2}{|c|}{ Alveolar } & \multirow{2}{*}{$\frac{\text { Palatal }}{\text { Laminal }}$} & \multirow{2}{*}{$\begin{array}{l}\text { Velar } \\
\text { Dorsal }\end{array}$} & \multirow{2}{*}{$\begin{array}{l}\text { Glotal } \\
\text { Glotal } \\
\end{array}$} \\
\hline & & & Labial & Apikal & Apikal & Laminal & & & \\
\hline $\begin{array}{l}\text { Letup } \\
\text { Hambat } \\
\text { hambat }\end{array}$ & $\begin{array}{l}\text { TB } \\
\text { B } \\
\text { TB }\end{array}$ & $\begin{array}{l}P \\
b\end{array}$ & & $\begin{array}{l}\mathrm{t} \\
\mathrm{d}\end{array}$ & & & $\begin{array}{l}c \\
j\end{array}$ & $\begin{array}{l}\mathrm{k} \\
\mathrm{g}\end{array}$ & $\mathrm{q}$ \\
\hline $\begin{array}{l}\text { Geseran } \\
\text { Frikatif }\end{array}$ & $\begin{array}{l}\text { TB } \\
\text { B }\end{array}$ & & & & $\mathrm{s}$ & & & & $\mathrm{h}$ \\
\hline Lateral & $\mathrm{B}$ & & & $\mathrm{r}$ & $\mathrm{L}$ & & & & \\
\hline Getar & $\mathrm{B}$ & $\mathrm{m}$ & & $\mathrm{n}$ & & & $\check{n}$ & $\mathrm{H}$ & \\
\hline Nasal & $\mathrm{B}$ & $\mathrm{w}$ & & & & & $\mathrm{y}$ & & \\
\hline
\end{tabular}

Contoh:

\begin{tabular}{|c|c|c|}
\hline [paIt] & 'pahit' & {$[\mathrm{p}]$} \\
\hline [udaך] & 'udang' & [d] \\
\hline 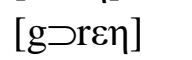 & 'goreng' & {$[\mathrm{g}]$} \\
\hline 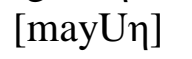 & 'rusa' & [m] \\
\hline$[j \supset \curvearrowright t]$ & 'nama buah' & [j] \\
\hline$[(\mathrm{te}) \mathrm{c} \supset \mathrm{tt}]$ & '(di)pecut,(di)cambuk' & [c] \\
\hline$[\supset \mathrm{s} \supset \mathrm{k}]$ & 'gosok' & {$[\mathrm{s}]$} \\
\hline [g $\supset \mathrm{l} \supset \mathrm{k}]$ & 'parang' & [1] \\
\hline [tipah] & 'tikar' & {$[\mathrm{h}]$} \\
\hline [tipaq] & 'tujuan' & [q] \\
\hline [tiwaך] & 'nama penyakit' & [w] \\
\hline [tiyaך] & 'saya' & [y] \\
\hline
\end{tabular}

\section{Ejaan dalam Bahasa Sasak}

Ada tiga prinsip tata aksara yang digunakan dalam menentukan ejaan standar bahasa Sasak. Pertama, tata aksara dalam bahasa Sasak harus menggunakan sistem grafemis bukan sistem fonemis. Hal ini dilakukan untuk melakukan penghematan lambang bunyi sehingga tidak terlalu banyak variasi yang dapat menyebabkan kebingungan. Kedua, alofon dari sebuah fonem yang sama hendaknya dilambangkan dengan satu grafem saja karena tidak mempengaruhi makna. Ketiga, bunyibunyi sengau/nasal hendaknya dilambangkan dengan dua grafem karena bunyi-bunyi tersebut sudah lazim digunakan dalam bahasa Indonesia yang notabene memiliki tradisi tulis yang lebih maju. Hal ini perlu dilakukan untuk menghindari kebingungan yang disebabkan oleh kebiasaan menggunakan dua lambang 
untuk merealisasikan fonem sengau

tersebut.

\begin{tabular}{|c|c|c|c|c|c|}
\hline \multirow[t]{2}{*}{ Fonem } & \multirow[t]{2}{*}{ Alofon } & \multirow[t]{2}{*}{ Grafem } & \multicolumn{3}{|c|}{ Contoh } \\
\hline & & & Fonetis & $\begin{array}{l}\text { Ejaan/ } \\
\text { grafemis }\end{array}$ & Glos \\
\hline \multirow[t]{2}{*}{ /i/ } & [i] & \multirow[t]{2}{*}{$\langle\mathrm{i}\rangle$} & idap & idap & $\operatorname{rasa}(k a n)$ \\
\hline & {$[\mathrm{I}]$} & & bait & bait & ambil \\
\hline \multirow[t]{2}{*}{$/ \mathrm{u} /$} & {$[\mathrm{u}]$} & \multirow[t]{2}{*}{$\langle\mathrm{u}\rangle$} & julu & julu & depan \\
\hline & [U] & & lauq & lauq & selatan \\
\hline /e/ & {$[\mathrm{e}]$} & $\langle\mathrm{e}\rangle$ & gawe & gawe & acara \\
\hline$/ \partial /$ & [ə] & $\langle\mathrm{e}\rangle$ & atəp & atep & atap \\
\hline$/ \varepsilon /$ & {$[\varepsilon]$} & $\langle\varepsilon\rangle$ & $\mathrm{b} \varepsilon \eta$ & beng & kasi \\
\hline$/ \mathrm{o} /$ & [o] & $\langle 0\rangle$ & koloq & koloq & taruh \\
\hline /ó/ & [ó] & <ó> & tóaq & toaq & tua \\
\hline$/ \mathrm{a} /$ & [a] & $\langle a\rangle$ & baIt & bait & ambil \\
\hline$/ \mathrm{p} /$ & [p] & $\langle p\rangle$ & paIt & pait & pahit \\
\hline$/ \mathrm{b} /$ & {$[\mathrm{b}]$} & $\langle\mathrm{b}\rangle$ & batu & batu & batu \\
\hline$/ \mathrm{t} /$ & {$[\mathrm{t}]$} & $\langle t\rangle$ & tam & tame & masuk \\
\hline
\end{tabular}

Ada beberapa prinsip tata tulis yang diterapkan dalam menentukan standardisasi ejaan bahasa Sasak. Pertama, bunyi dalam bahasa Sasak yang kedengarannya hadir sebagai gugus konsonan hendaknya ditulis dengan menyisipkan grafem $\langle\mathrm{e}\rangle$ di antara konsonan tersebut sebagai realisasi dari bunyi [ə]. Hal ini bertujuan untuk memudahkan proses penyukuan kata. Misalnya, [kdb $\supset \eta$ ]'batang pisang' $<$ kedebóng $>$, [smt $\supset$ n]'saudara' $<$ semetón $>$, [krujuq]'kepiting' $<$ kerujuq $>$, [gr $\supset$ bak]'gerobak'<gerobak $>$. Kedua, pemenggalan kata harus dilakukan berdasarkan atas pelafalan lisan seperti pemakaian bahasa dalam kehidupan sehari-hari. Misalnya, <kedebóng> 'batang pisang' ked-eb-óng, $<$ semetón>'saudara'sem-et-ón, $<$ kedek> 'main-main' kedek. Namun begitu, leksikon tertentu dalam bahasa Sasak kadang terdengar mengandung konsonan geminat, tetapi bunyi tersebut sesungguhnya tidak demikian. Hal tersebut, kedengaran terdapat konsonan geminat, dapat terjadi karena dalam bahasa Sasak sering terdapat suku kata tertutup pada posisi selain 
ultima, berbeda dengan bahasa Indonesia.

Misalnya $<$ kedebóng $>$ 'batang pisang'*ke-de-bóng,

$<$ semetón>'saudara'*se-me-tón,

dan $<$ kedek $>$ 'main-main'*ke-

dek.Ketiga, klitika $\{\mathrm{n}\}$ 'dia', $\{\mathrm{k}\}$ 'aku', $\{\mathrm{t}\}$ 'kita/kami', $\{\mathrm{m}\}$ 'kamu' dalam bahasa Sasak (standar) hendaknya ditulis/direalisasikan dengan $\{$ nə\}, $\{k ə\},\{$ tə $\},\{m ə\}$. Hal ini dilakukan untuk memperjelas jenis klitika yang menjadi realisasi dari pronomina dalam bahasa Sasak tersebut. Dengan demikian, pengidentifikasian jenis klitika tersebut akan menjadi mudah dilakukan dalam pemakaian (bahasa lisan) sehari-hari. Keempat, bunyibunyi yang dalam bahasa tutur seharihari dengan pelafalan [ə] pada posisi ultima hendaknya direalisasikan dengan <o> pula. Hal ini dilakukan untuk menyeragamkan antara ucapan dan tulisan. Misalnya, Swetə, Sakro, Cakrə, Padəmarə, Srinatə, dan sebagainya.

\section{Simpulan}

Kajian standardisasi bahasa Sasak terutama ejaan telah cukup memadai karena memenuhi unsur ilmiah dengan melakukan pertimbangan secara linguistik dan sosiolinguistik dan faktor sosiologis dengan mempertimbangkan sikap bahasa penutur dialek-dialek bahasa Sasak. Diperlukan desiminasi menyeluruh dan berkelanjutan sampai pada pengajaran bahasa Sasak di sekolah. 


\section{DAFTAR PUSTAKA}

${ }^{1}$ Mahsun, 2006. Kajian Dialektologi Diakronis Bahasa Sasak di Pulau Lombok. Yogyakarta: Gama Media

${ }^{2}$ Bappeda Provinsi Nusa Tenggara Barat dan Yayasan Abdi Insani. 2005. 'Standardisasi Ejaan dan Tata Bahasa Sasak.'

${ }^{3}$ Ahmad Sirulhaq, dkk., 2009. 'Kajian Standardisasi Dialek Bahasa Sasak'. Laporan Penelitian: Kantor Bahasa Provinsi NTB

${ }^{4}$ Mahsun, 2005. Metode Penelitian Bahasa. Jakarta: Rajawali Press

${ }^{5}$ Sudaryanto, 1993. Metode dan Aneka Teknik Analisis Data. Yogyakarta: Duta Wacana University Press

${ }^{6}$ Mahsun, 2005. Metode Penelitian Bahasa. Jakarta: Rajawali Press

${ }^{7}$ Sudaryanto, 1993. Metode dan Aneka Teknik Analisis Data. Yogyakarta: Duta Wacana University Press 